Revista de Comunicación y Salud, 2019, Vol. 9, n 1, pp. 39-49

Editado por Cátedra de Comunicación y Salud

ISSN: 2173-1675

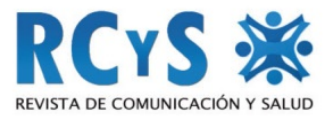

Enviado 04/04/2019

Aprobado 20/05/2019

\title{
EL COLOR DE LA PIEL UN FACTOR DE DISCRIMINACIÓN EN LA EDUCACIÓN CUBANA
}

\author{
Skin color a discriminating factor in Cuban education
}

Luisa M. Martínez O'Farrill ${ }^{12}$

Universidad de Ciencias Pedagógicas "Enrique José Varona". Cuba.

luisamo@ucpejv.edu.cu

\section{Cómo citar el artículo}

Martínez O'Farrill, L. M. (2019). El color de la piel un factor de discriminación en la educación cubana. Revista de Comunicación y Salud, 9(1), 39-49.

doi: http://doi.org/10.35669/revistadecomunicacionysalud.2019.9(1).39-49

\section{INTRODUCCIÓN}

Pocas veces al abordar el tema del negro en Cuba o se aborda la educación se presentan investigaciones que profundicen en este aspecto. Las formas más usuales han sido el tratamiento como parte de la labor de instrucción de las sociedades, asociaciones de africanos y descendientes, en las que tuvo un papel descollante desde fines del siglo XIX y durante las primeras décadas del siglo XX, Juan Gualberto Gómez al frente del Directorio de la raza de color en Cuba.

Su profunda preocupación por dotar a este grupo humano en un peldaño social digno, con oportunidades de progreso y empleo en ramos representativos de la vida social y no sólo en ocupaciones igualmente dignas, pero que por su naturaleza no exigían de preparación intelectual por ser eminentemente físicas.

Para Juan Gualberto Gómez la cultura debía ser un bastión a conquistar por la raza de color y desde su alcance estaría conquistando un tratamiento digno en

\footnotetext{
${ }^{1}$ Autor para correspondencia: Luisa M. Martínez O'Farrill luisamo@ucpejv.edu.cu, luisa7247@nauta.cu, martinezofarilluisa@gmail.com

${ }^{2}$ La tesis La filosofía de la educación en las sociedades de instrucción y recreo en Cuba, fue presentada por la autora en opción al grado científico de Doctor en Ciencias Filosóficas, 2008.
} 
correspondencia con sus capacidades e ingenio, dejando de ser considerados salvajes por tener lazos con África.

Resultó una sorpresa para la autora, que abordó en una ocasión anterior, en evento de la localidad de Orozco, Bahía Honda, el tema de la educación social en africanos y descendientes, encontrar un pequeño texto de Salvador García Agüero en que acaparaba su atención este asunto de la presencia del negro en la educación.

El texto pertenecía a una conferencia leída el 30 de diciembre de $1937^{3}$, hace ochenta y un años, fuera presentada en el Palacio Municipal como parte de la serie Habaneros llustres, publicada en el No. 11 de los Cuadernos de Historia Habanera, y valga esta presentación para rendir homenaje a La Habana en su 500 cumpleaños. Al mismo tiempo, estamos en este contexto reconociendo a un habitante de la ciudad, residente en el barrio de Jesús María perteneciente al municipio La Habana Vieja, figura destacada de la historia social cubana.

\section{EL DIRECTORIO DE LA RAZA DE COLOR. LABOR DE JUAN GUALBERTO GÓMEZ}

La presencia del Directorio de la Raza de Color hay que buscarla en las postrimerías del siglo XIX, período testigo de la puesta en vigor de la Ley de Asociaciones por la Metrópolis española tanto para la nación como para los territorios españoles de ultramar. Esta ley de 1877 puso en vigor el registro oficial de cabildos, cofradías, sociedades, asociaciones, fraternidades, hermandades, iglesias, etc., existentes en la Isla de Cuba para legalizar su status, derechos y obligaciones, así como la continuidad de funciones.

El período es complejo para la raza de color, ya que los cabildos, ermitas de oración y sociedades debían enfrentar este proceso con una desventaja natural, la lengua y por otro lado el dominio de una legislación y cultura social que les resultaba " extraña " si tomamos en cuenta el corto período entre el cese total de la esclavitud, los cambios en la vida de subsistencia de los otrora esclavos, así como la obligatoriedad de participar en un proceso jurídico si querían conservar el único espacio real que poseían para la práctica de sus culturas de origen.

A esta situación objetiva se suman las escaramuzas legales por la obligatoriedad de participar bajo la advocación de un determinado santo católico, establecida por la anterior legislación como condición insoslayable para la admisión del funcionamiento de estas agrupaciones de negros. Lo que implicaría en este presente batallas legales contra las intenciones de la Iglesia Católica de apropiarse de las propiedades del cabildo, fueran casas, terrenos, muebles, etc., agravado este panorama por el desconocimiento de la lengua española, sobre todo entre el grupo de esclavos de nación. Timados por descendientes y españoles, fueron fuertes algunos procesos de

${ }^{3}$ La conferencia consta de 28 páginas. 
legitimidad de derechos librados en este período, por lo que la preparación para la vida social pasó a convertirse en un imperativo de primer orden.

Juan Gualberto Gómez se erige así en la figura representativa para el cambio que requiere la raza de color, por sus orígenes biológicos, su oportunidad, cultura, su sentido de identidad nacional e identidad socio racial, le convocan a participar en la intención de proporcionar a este grupo etnoracial una preparación educacional que le permitiera ascender hacia mejores oportunidades laborales, de vida y representación social.

Para Juan Gualberto Gómez la cultura debía ser un bastión a conquistar por la raza de color y desde su alcance estaría conquistando un tratamiento digno en correspondencia con sus capacidades e ingenio, dejando de ser considerados salvajes por tener lazos con África. Con esta idea en mente, trabaja por la constitución del Directorio Central de las Sociedades de la raza de color, con domicilio en el centro de cocheros de la ciudad de La Habana, su creación el 2 de junio de 1887.

La finalidad: responde a la necesidad de aunar esfuerzos en pró del bienestar moral y material de esta raza. En artículo del propio Juan Gualberto Gómez, publicado en La Igualdad, el 15 de junio de 1892 en La Habana, con el título Lo que es el Directorio, respondía a preguntas provenientes de distintas partes de la Isla acerca del carácter y misión del mismo, explica:

"El esfuerzo intelectual de la clase de color, desde la implantación del régimen en vigor, se dirigió al establecimiento de Sociedades de Instrucción y Recreo que se han ido creando en las principales poblaciones y que por el hecho de ser las únicas colectividades organizadas por los hombres de nuestra raza, son también las que más legítimamente ostentan por los pueblos su representación."

El Directorio se crea para aunar los esfuerzos parciales de todas las Sociedades de la Raza de color. El artículo 1. Refiere está formado por la representación de todas las sociedades de la misma raza:

$\checkmark$ Centro de cocheros,

$\checkmark$ Centro de cocineros,

$\checkmark$ Bella unión habanera,

$\checkmark$ Amigos del progreso,

$\checkmark$ Nuestra Señora de las Mercedes

$\checkmark$ Sociedad Purísima Concepción

$\checkmark$ Nuestra Señora de Guadalupe

$\checkmark$ Divina Caridad,

$\checkmark$ Nuestra Señora de la Cinta

$\checkmark$ Nuestra Señora de Regla,

$\checkmark$ Artesanos de La Habana,

${ }^{4}$ En página 1, párrafo 2

Revista de Comunicación y Salud, 2019, Vol. 9, n 1, pp. 39-49 
$\checkmark$ Nuestra Señora de Monserrate,

$\checkmark$ Buen suceso

$\checkmark$ Detroit, etc.

El domicilio de la asociación, Directorio de la Raza de Color radicó en la calle Aguacate No. 6 desde el 20 de septiembre de 1888.

En sus bases generales, Capítulo 3 , artículo $5^{\circ}$ declara su objeto principal es mantener una representación seria y autorizada cerca de las autoridades, Centros Benéficos, Abolicionistas, Sociedad Económica, Centros Superiores de Educación y todos aquellos de quienes se pueda recabar dentro de la más estrecha legalidad la protección y mejoría de los intereses de la raza negra en los distintos órdenes de la vida.

El artículo $6^{\circ}$. Declara que propenderá por cuantos medios lícitos estén a su alcance, a la mejora de las costumbres, moralidad, comunidad de aspiraciones, propagación de conocimientos útiles y en definitiva a cuanto directa e indirectamente pueda redundar en beneficio de la raza negra.

Artículo $7^{\circ}$ Propenderá así mismo, como consecuencia del fraternal espíritu que la anima a establecer base inquebrantable de la comunidad de intereses y aspiraciones, la más estrecha unión con todos los centros de Instrucción y Recreo, Socorros Mutuos, Cofradías, etc. etc., a propósito de evitar colisiones, antagonismos y toda clase de dificultad que pueda entorpecer la progresiva marcha de los mismos. (...)

Los siguientes artículos son esenciales para la educación, así refiere el artículo $8^{\circ} \mathrm{Se}$ solicitará la creación de Colegios de Primeras Letras para niños de ambos sexos y en su defecto la admisión en los establecimientos para niños de ambas razas.

Artículo $9^{\circ}$ Gestionará la conducente colocación e ingreso de jóvenes de color en la Universidad, Institutos Provinciales, Escuelas Profesionales, Normales, etc., etc., ya costeando su enseñanza, ya solicitando opción a olas plazas gratuitas, que como merced se otorgan ú otorgaren, como así mismo el ingreso en la Real Casa de Beneficiencia de los niños desvalidos.

Artículo $10^{\circ}$ Considerando el desarrollo de la Instrucción única base de nuestra prosperidad futura atenderá con preferencia a la creación de cantos colegios laicos le sea posible; organizará conferencias sobre temas instructivos, certámenes y funciones cuya índole sea constante estímulo para los individuos de nuestra raza.

Más adelante sintetiza,' Como se ve el Directorio viene a ser algo así como la concentración de la clase de color de Cuba que se lleva a cabo con el objeto de tener una representación que pueda en todos los casos gestionar cerca de las Autoridades, Poderes Públicos y de las Corporaciones, así oficiales como privadas, todo lo que interese al hombre negro en las diversas esferas de a vida social. 
Denuncia, a cada instante se producen sucesos que afectan a toda la clase de color o que lastimando a individuos de su seno revisten naturaleza tan genérica que de rechazo hieren o interesan a la clase de color en general. (...)

El Directorio es un gran grupo social constituido, inútil parece considerar que en su seno no caben las luchas políticas, las controversias religiosas, por ello llama a la integración y unidad del grupo a sumarse con independencia de la filiación política o religiosa.

Por su carácter el Directorio aspira a ser el representante de la Raza de Color en la Isla de Cuba. Da cabida a todos los hombres de todas las opiniones, respeta los problemas políticos y generales de Cuba, como a los participantes y privativos de la raza de color. Los acuerdos se toman por mayoría.

Esta asociación fue cancelada como Directorio, el 21 de agosto de 1891, no así las diferentes sociedades que lo constituyeron, las que siguieron una trayectoria independiente a lo largo del siglo XX, por ejemplo las Sociedades de Instrucción y Recreo, conocidas popularmente como Sociedades de Negros existentes a lo largo de toda la geografía nacional.

\section{LA EVIDENCIA INVESTIGATIVA LEGADA POR SALVADOR GARCÍA AGÜERO EN RELACIÓN CON LA EDUCACIÓN CUBANA}

En la conferencia habló de Lorenzo Meléndez un Teniente del Batallón de Granaderos Pardos, nacido hacia la mitad del siglo XVIII, mulato, con actuación notable durante la defensa de La Habana, hasta el punto de estar dispuesto a haberse hecho matar por defenderla contra el invasor inglés, actitud que denota su sentido de pertenencia con el lugar de residencia y nacimiento.

Meléndez se hizo maestro por vocación altruista en unión de Mariano Moya, pardo libre como él, que con visión esclarecedora advirtió que la instrucción, comprensión y amor cooperadores en la rectificación de brutales prejuicios en el alma de la raza dominante era un factor importante para la recuperación de la raza de color de su autoestima, dignidad y valoración como seres humanos.

Su escuela fue de alto crédito, se impartía lectura, escritura, cuentas, gramática y ortografía, llegó a tener una matrícula de ciento veinte alumnos, de ellos cuarenta blancos y ochenta de color, una cifra elevada para la época y el estado de la educación.

Fray Félix González contemporáneo de Meléndez, la describe muy bien cuando caracteriza, " el corto estipendio dado a los maestros apenas podía alcanzarles para una casa reducida y vivir con escasez y miseria, (...), más adelante agrega, sólo el infeliz e inútil podía aplicarse a ser maestro y dejarlo al encontrar ocasión que le 
ofreciese más ganancia y comodidad, porque cualquiera que se aplicase a otro ejercicio de menos sujeción y tarea sacaba más fruto de su trabajo ${ }^{5}$."

Las líneas escritas por el fraile ponen al descubierto la penosa situación del maestro, la entrega requerida y las convicciones personales como fuerza impulsora acerca de la necesidad de este servicio para en lugar de ocuparse en actividad mejor remunerada y compensada económicamente, optar por ésta. Por otro lado, si consideramos la anterior vida militar de Meléndez donde las oportunidades de salario eran superiores, podemos entender por qué Salvador García Agüero califica de altruista su elección y tiene en alta estima su quehacer, al punto de escribir una conferencia sobre este maestro olvidado con el paso del tiempo; pero que dignifica el sentido del servicio a la sociedad que brinda el magisterio con su quehacer.

Interesante resulta y mucho que desear nos deja en sentido contrario, la reflexión pragmática del " hacedor de almas y normas morales ", el fraile González, y su calificativo de "infeliz e inútil " para aquellos que privilegiaron el bienestar de muchos en detrimento del personal. Una dicotomía hipócrita entre pensamiento y práctica, con respecto a lo que debió predicar en su labor cotidiana.

García Agüero aporta otros datos que indican la preocupación e interés que este tema le generó y aporta información sobre:

- Durante los siglos XVI - XVIII la enseñanza primaria y la cultura, no fueron importantes o una preocupación sensible en la sociedad colonial.

- Por 1569 fue fundada una escuela por Juan Roger, misionero español, donde Juan B. Segura ${ }^{6}$ enseñó, en ella, por un tiempo a niños indios.

- Fija en 1605 año de existencia fugaz de la primera escuela en La Habana.

- Señala que es en el siglo XVIII, con posterioridad a la ocupación inglesa que se inicia la inquietud intelectual sobre la necesidad de ampliar la capacidad instructiva y vincula a esta intención la aparición de las primeras escuelas conventuales, cita en este marco como ejemplo la escuela del Convento de Belén ${ }^{7}$ y la labor de Fray González en ella.

- Destaca la influencia de Don Luis de las Casas ${ }^{8}$, Gobernador General en 1790 y el impulso a la creación de la Sociedad Patriótica de la Habana en $1793^{9}$.

\footnotetext{
${ }^{5}$ Citado en página 10 - 11 de la mencionada conferencia impartida por Salvador García Agüero.

${ }^{6}$ No esclarece en el texto citado si Juan B. Segura es negro.

${ }^{7}$ Ubicado geográficamente en la actual Habana Vieja, donde a pesar de los años se yergue majestuoso, su gran capacidad en áreas permite hacerse una idea de la complejidad de la instrucción allí desarrollada y donde se atendían entre 600 y 800 niños de todas las edades por un solo fraile. Fe de ello aporta el primer censo sobre la situación de la instrucción y las primeras letras en Cuba, ordenado por la Sección de Educación de la Sociedad Patriótica de la Habana en 1816, así como Bachiller y Morales en su libro sobre el mismo tema.

${ }^{8}$ Gobernador que marca el período de la llustración en Cuba, notable por su apoyo a la cultura y su fomento. Su período es conocido como Despotismo ilustrado.
} 
- Resalta a Antonio Bachiller y Morales, reconocido primer bibliógrafo cubano ${ }^{10}$, como prejuicioso y hostil al negro como la mayoría social de su tiempo, repudió el contacto entre negros y blancos, se declaró además contrario a la instrucción llevada a cabo por negros y pardos, al respecto García Agüero ${ }^{11}$ cita: " la raza más envilecida y la más ignorante, enseñará a la caucásica. Y, Esta rareza producía otra que desde luego procuró destruir la Sociedad Económica, la confusión en un mismo recinto, de todos los colores y castas, fomentando de esa manera, desde la infancia, ese elemento de confusión moral que trae de suyo la inevitable familiaridad de los jóvenes de diversas condiciones en los países esclavos.

La amplitud cultural de Salvador García Agüero queda expuesta cuando reconoce de conformidad con Hegel que "la marcha de las ideas es consecuencia de la marcha de las cosas; la marcha del pensamiento se explica por la marcha de la vida ${ }^{12}$. " Con esta cita cierra la valoración acerca de la postura de Antonio Bachiller y Morales.

Apunta que en 1809 se redacta el primer reglamento para el Gobierno de Maestros, que no llegó a hacerse firme y se dejó a la elección de cada maestro; pretendía negar a los negros toda instrucción, lo que debe haber suscitado grandes debates que provocaron quedara abierto el asunto.

Explica con cita de José Antonio Saco ${ }^{13}, 1797$ - 1879, su pensamiento cuando dijo * abolióse la costumbre de que los niños de ambos sexos se reuniesen en una sala, y de que se hallasen mezclados las razas blancas y africanas. Prohibióse además el magisterio de la gente libre de color, aunque se les toleraba ejercerlo limitadamente con los de su misma raza."

Fue profesor en el colegio Buenavista, de La Habana, tuvo gran influencia en el desarrollo de la educación y de la cultura cubana en general del siglo XIX. Para él, (...) la instrucción pública es la base más firme sobre la que descansa la felicidad de los pueblos (...) Establezcamos pues, para los pobres que no pueden costear su educación, el competente número de escuelas en todos los pueblos y campos.

\footnotetext{
${ }^{9}$ La creación de la Sociedad Patriótica en la Habana es parte de una estrategia real española de fomento de la industria, la ampliación de las ocupaciones económicas con bases en el conocimiento y la aplicación de nuevas técnicas productivas, así como de la instrucción como la vía para potenciarlas.

${ }^{10}$ El pensamiento de Bachiller con respecto a la discriminación racial es prueba palpable del pensamiento de la época, de una psicología social de amplia implicación política de poder sobre los grupos dominados, en este caso indios, mestizos y negros, así como su descendencia. Esto no obvia, el reconocimiento a su valiosa labor intelectual, impulsora del libro y el conocimiento. Pero la admisión de que fue un hombre de su tiempo, y la puesta al descubierto de su pensamiento discriminante por color de la piel, refleja su pertenencia a su siglo y tiempo histórico que le tocó vivir.

${ }^{11}$ Los datos citados aparecen en las páginas 13 y 14 de la citada conferencia.

12 En página 19 de la conferencia.

${ }^{13}$ José Antonio Saco y López Cisneros (Bayamo, Cuba, 7 de mayo de 1797 - Barcelona, España, 26 de septiembre de 1879) fue un sociólogo, periodista, historiador y economista cubano. Dio a conocer la identidad nacional cubana, se opuso a la corriente anexionista con Estados Unidos que existía en la isla por aquella fecha.
} 
Esta figura controvertida de la historia nacional fue anti-esclavista convencido, pero rechazó siempre los principios humanitarios del abolicionismo. Esta posición descansaba en el convencimiento de que los negros, esclavos o libertos, eran el principal enemigo de la nacionalidad cubana, que circunscribía a los criollos blancos.

El análisis realizado puso al descubierto la agudeza del asunto, las pasiones despertadas, las posiciones que se enfrentaban a favor y en contra. Argumenta con datos y ejemplos, como el caso del 13 de diciembre de 1827 en que el Ayuntamiento de la Habana negó a la morena libre Ana del Toro el permiso para la enseñanza de las Primeras Letras a niñas de color. Así como, describe las ideas de Félix Varela acerca del derecho de todos a la instrucción y de Juan Gualberto Gómez en contra de la separación de blancos y negros en las aulas.

Aporta algunos datos estadísticos que toma de Trelles, para hacer una comparación sencilla, no por ello menos valiosa acerca de la situación social del negro ante la educación. No obstante, tiene el valor agregado de ser suficientemente instructiva para apreciar la urgencia de la educación como necesidad de la sociedad y la cercana paridad de desventaja entre los grupos comparados en el siglo XX, alarmante la disparidad en el siglo XIX. Aunque mínimo el acceso a la educación para ambos grupos.

\begin{tabular}{|c|c|c|}
\hline \multicolumn{3}{|c|}{ EN CUBA SABEN LEER } \\
\hline AÑOS & BLANCOS & NEGROS \\
\hline 1862 & $30 \%$ & $4 \%$ \\
\hline 1920 & $49 \%$ & $44 \%$ \\
\hline
\end{tabular}

- Para 1937 existen en ejercicio 1170 Maestros Negros.

Cierra con los aportes del grupo Negro a la educación y destaca que la alternativa la encontró en la creación de las Sociedades Culturales de instrucción y recreo ${ }^{14}$, tanto en el país como en la emigración, cita como ejemplos de éstas últimas:

- Sociedad "El Progreso " en Key West

- Sociedad "La Verdad", Tampa.

- Sociedad "La Liga ", New York

El trabajo de Salvador García Agüero con el objetivo de preparar la conferencia y argumentos sobre la educación del negro en Cuba, nos coloca en la posición de apreciar este ámbito como un escenario crucial de lucha por la igualdad social, así la importancia que asume a lo largo de la historia nacional, nos aproxima a la dimensión de esta figura que se cuenta entre las menos estudiadas por las generaciones del presente y a la que como a la de Meléndez le hiciera él en 1937 hay que hacerle justicia en el 2018 y futuro próximo.

\footnotetext{
${ }^{14}$ A estas escuelas existentes en el seno de las sociedades asistían niños de cualquier grupo racial, tanto en Cuba como en el extranjero.
} 
¿Pero fueron Meléndez y Moya los únicos individuos " de color ${ }^{15}$ " ocupados en la educación por este tiempo?, ¿han sido ellos los únicos olvidados?

No han sido los únicos me atrevo a responder, ya que coloco a disposición de todos los presentes y los que puedan leer estas páginas algunos nombres acompañados de detalles acerca de la labor que desarrollaron como maestros. Reconozco que no todo lo enjundiosa que me habría gustado, pues la búsqueda de mayor información es compleja; pero al menos se abre el camino a la espera de más empeño en esta dirección.

Fueron Maestros destacados en el siglo XIX:

1. MATÍAS VELASCO, hijo de esclava y sacerdote. Hombre de profundos conocimientos sobre leyes, lo que provocaba que a las tertulias que ofrecía asistieran letrados de su tiempo, que le escuchaban y discutían con respeto.

2. JOSÉ CALZADA, fue un individuo que recibió elogios en la prensa de la época, por 1826 sostuvo una escuela en la que aprendían niños de diferentes razas, ejerció en su escuela como maestro Don Agustín Botey que más tarde sería rector de los Escolapios.

3. FRANCISCO PASTOR RODRÍGUEZ, dentista como el padre, funda en 1866 el primer Depósito Dental de la América Española, en 1879 la Sociedad Odontológica de La Habana y en 1881 el Colegio Dental " El Progreso."

4. SECUNDINO ARANGO, violoncelista notabilísimo solicitado por las Compañías de Ópera extranjeras, dominaba numerosos instrumentos. Fue un maestro de música conocido y famoso por su quehacer. Contó como discípulos con:

- José Silvestre White

- Francisco de Paula Arango, su hijo, más tarde violinista eminente y profesor de la Academia de Música de la Habana.

5. JUANA PASTOR, maestra y poetisa nacida en el Barrio de Jesús María y José, versadísima en aritmética, geometría, gramática y latín, murió ejerciendo su profesión. Fue mentora de las más distinguidas damas de su tiempo.

6. ANTONIO MEDINA, poeta comediógrafo, sastre y maestro, residió en la calle Jesús María, barrio San Isidro, en la Habana Vieja. Fue maestro de Juan Gualberto Gómez.

7. LEÓN MONZÓN, maestro habanero, deportado a España acusado de conspirador, fundó en La Coruña una escuela.

8. PILAR BORREGO, maestra habanera muy preocupada por la ilustración de la mujer negra, fue deportada junto con León Monzón y con éste fue cofundadora de la escuela en La Coruña.

\footnotetext{
${ }^{15}$ Calificativo empleado en Cuba durante los siglos XV al XXI para establecer las diferencias entre * blancos " y los otros " indios, mestizos y negros." Esta denominación encierra profundas raíces discriminantes, prejuiciosas, de desigualdad social por razones de color de la piel. Lamentablemente presentes todavía en la psicología social, a pesar de la educación, instrucción y cultura social al acceso de la población. Indicador de la resistencia del prejuicio y emociones negativas ante el cambio social.
} 


\section{CONSIDERACIONES FINALES}

- Ha sido encomiable la labor de Salvador García Agüero para hablar de los maestros negros y los esfuerzos de este grupo humano por llevar a cabo la necesaria educación que dignifica al ser humano y lo coloca en mejor posición para enfrentar la vida. Al mismo tiempo, nos brindó una oportunidad de acercamiento a una figura poco estudiada de nuestra historia nacional.

- El asunto del acceso a la educación fue a lo largo de nuestra historia y hasta 1959 en que triunfó la Revolución de la que somos herederos, un asunto de lucha política por la igualdad de derechos sociales, contra la discriminación racial y de justicia social.

- Recordar, investigar y socializar los resultados es en estos tiempos una forma de contribución a la cultura general integral sobre la profesión y al combate desde la profesión contra el estigma ideopolítico de la diferenciación social por color de la piel.

\section{BIBLIOGRAFÍA CONSULTADA}

Archivo Nacional de Cuba. 1887. Expediente promovido por el Sr. Juan Gualberto Gómez para fundar Directorio de la Raza de Color. Fondo Asociaciones.

1940. Actas. Legajo 13, número 14. Expedientes $3 / 10$ y $4 / 11$ referentes a la organización de la enseñanza y la cultura. Fondo: Convención Constituyente.

Castro Ruz, Fidel. 2000. Discurso de Fidel Castro del 8 de septiembre, en la iglesia Riverside Harlem, Nueva York.

García Agüero, Salvador. 1937. Conferencia: El negro en la educación, (sin fecha edición)

Ibarra Cuesta, Jorge. Varela el precursor. Un estudio de la época. Editorial Ciencias Sociales, 2004.

Martí Pérez, José. Mis Negros. Obras Completas, tomo 18, página 285.

1889. Carta a Serafín Bello del 16 de noviembre. Obras Completas, tomo 18.

1882. Carta a Antonio Maceo. New York, 20 de julio. Obras Completas.

Para un libro Carta a Rafael Serra. OC, tomo 1, p. 298.

Martínez O'Farrill, Luisa. 2017. La historiografía en el análisis del negro en Cuba. Revista Tlatemoani. No. 24, abril - junio. ISSN: 1989-9300. WWW.eumed.net 
2018. Libro: Yo soy el otro en la historia social de Cuba. Editorial Académica Española (eae), marca comercial de: OmniScriptum GmbH \& Co. KG, libro 35791, ISBN 978-620-2-10088-5, abril.

para la diversidad, sus fundamentos filosóficos y sociológicos en el estudio de la discriminación social. Experiencias realizadas. Coloquio Nacional de Pedagogía. Facultad de Ciencias de la Educación, julio 20 y 21, UCPEJV.

MES. Carta a los Rectores. 2014. RS 008. Dirección de Marxismo Leninismo e Historia. Ref. 838-2367. La Habana.

Periódico Granma, viernes 20 de 2018. Intervención del 1er Secretario del PCC Raúl Castro Ruz en la clausura de la Sesión Constitutiva de la IX Legislatura de la Asamblea Nacional del Poder Popular, Palacio de Convenciones, jueves.

Unesco, 2005. Convención internacional sobre la promoción y respeto a la diversidad cultural, París. Francia 